\title{
A FORMAÇÃO DE PROFESSORES EM ARTES VISUAIS E O ENSINO MÉDIO: APRENDER E ENSINAR EM TEMPOS DE TRANSIÇÃO
}

\section{TEACHER TRAINING IN VISUAL ARTS AND HIGH SCHOOL: LEARNING AND TEACHING IN TIMES OF TRANSITION}

\author{
FERREIRA, Luis Carlos Pinheiro ${ }^{1}$ \\ CAIXETA, Ana Paula Aparecida²
}

\begin{abstract}
ResUmo
O texto apresenta um olhar sobre a Disciplina de Estágio Supervisionado, ministrada a estudantes do Curso de Licenciatura em Artes Visuais, como forma de compreender como as experiências vivenciadas neste contexto formativo são parte importante na construção de conhecimento. Este olhar atenta-se à formação dos discentes para o contexto da educação básica relacionando-se com o estudo e a pesquisa docente. Apontamos questões que envolvem a percepção e a reflexão crítica no que concerne às mudanças curriculares relacionadas com a contemporaneidade, assim como o ensinar e aprender em tempos de transição.
\end{abstract}

PALAVRAS-CHAVE: Formação; Artes Visuais; Experiências; Ensinar e aprender.

\section{ABSTRACT}

The text presents a look into the discipline of supervised internship, taught to the students of degree in Visual Arts, as a way to understand how the formative experiences in this context are an important part in the construction of knowledge. This view focuses on the formation of students in the context of basic education relating to the study and teaching research. We point out issues involving perception and critical reflection regarding contemporary curricular changes, as well as teaching and learning in times of transition.

KeYwORDS: Training; Visual Arts; Experiences; Teaching and learning.

\footnotetext{
${ }^{1}$ Professor Adjunto no Instituto de Artes da Universidade de Brasília. Doutor em Arte e Cultura Visual pelo Programa de Pós-Graduação em Arte e Cultura Visual da Universidade Federal de Goiás. Goiás, GO, Brasil. e-mail: luizcpferreira@gmail.com

${ }^{2}$ Professora Adjunta do Departamento de Artes Visuais da Universidade de Brasília e do Programa de Pós-Graduação em Literatura (POSLIT/UNB). Doutora e mestre em Literatura pela Universidade de Brasília (UnB). Graduada em Artes Plásticas (UnB) e Letras (CESB/ICSH). Goiás, GO, Brasil. e-mail: caixetaanapaula@yahoo.com.br
} 


\section{INTRODUÇÃO}

O presente artigo contempla reflexões sobre a Disciplina de Estágio Supervisionado em Artes Visuais e observações a partir de experiências vivenciadas por docentes que atuam no Curso de Licenciatura em Artes Visuais. Enquanto os apontamentos buscam uma reflexão do lugar do Estágio no contexto formativo do Ensino em Artes Visuais, as experiências pontuam contextos narrativos que transitam entre a trajetória docente dos professores e os desafios de aprender e ensinar em tempos de transição. Quando mencionamos esses desafios, estamos pensando sobre o contexto político que envolve o cenário educativo atual. Nesse aspecto, não podemos desconsiderar nossa trajetória formativa tanto na dimensão da graduação e na formação continuada como na própria experiência docente na educação básica.

Ao refletirmos sobre a nossa prática docente, sobretudo, pelo olhar atento que envolve a formação de professores, estamos em constante movimento de entendimento sobre os novos paradigmas na educação, especialmente, ao consideramos que os desafios do aprender e ensinar na contemporaneidade são diversos e exigem dos docentes esforços conscientes que ultrapassem ações didáticas ausentes de reflexão. Esses esforços residem tanto na postura ética e estética da profissão docente como na forma de compreender as mudanças provocadas por rupturas epistemológicas, que afetam sobremaneira a práxis docente e a receptividade discente. Nesse aspecto, quais seriam os impactos das novas políticas no contexto da educação básica? Quais os efeitos e os reflexos de uma reforma curricular no contexto do ensino médio, sobretudo para a disciplina de artes visuais? Tais indagações permeiam o nosso cotidiano, alertando-nos, continuamente, sobre os impactos de uma mudança que está prestes a invadir a sala de aula e que nos requer um olhar que vincule a Universidade à pratica na educação básica de modo dialógico, horizontal e atento. É neste ponto que observamos como as práticas de estágio docente podem fazer essa ponte, não apenas por levar os graduandos à sala de aula, mas por entender que quem abre esse espaço de ensino, reflexão e prática é a escola de educação básica - aqui, em especial, a experiência com o Ensino Médio.

\section{A POSTURA ÉTICA E ESTÉTICA: UM LUGAR DE ESTÁGIO SUPERVISIONADO}

A prática docente, em sua gênese, envolve o gesto formativo como ação que contempla uma consciência atenta aos cuidados, escolhas e norteamentos instrutivos, interessados na construção e no desempenho de habilidades para se lidar com as questões de si enquanto sujeitos históricos, sociais, culturais e estéticos. Nesse sentido, é próprio do lugar da docência enfrentar o universo complexo da Ética e da Estética, duas ciências filosóficas com suas epistemologias, que, 
DOI: $10.12957 / \mathrm{e}-\mathrm{mosaicos} .2019 .46561$

historicamente, compõem formas de se lidar com os paradigmas do tempo.

Lalande (1993) nos dirá que a Ética, em seu contexto histórico, foi aplicada sinonimamente à Moral e interferia nas ações e decisões em caráter de escolha entre às ideias de bem e de mal. Contudo, Ética se difere da Moral, especialmente por esta compreender um conjunto de regras elegidas por um determinado grupo, enquanto aquela é a "ciência que toma por objeto imediato os juízos de apreciação sobre os atos qualificados como bons ou maus" (LALANDE, 1993, p. 349). O que nos chama atenção à descrição de Lalande é destacar os juízos de apreciação como ponto importante no quesito ética, o que, no contexto formativo, fomenta uma importante discussão no que tange a reflexão sobre a prática docente e suas emergências cotidianas.

Não nos parece haver dissociação entre um olhar ético e o contexto pedagógico quando se pensa que a formação, enquanto prática, é genuinamente reflexiva e lida constantemente com a imprevisibilidade, considerando aquilo que Nóvoa (2017) nos chama atenção, quando nos provoca a pensar a sala de aula em suas instâncias múltiplas e suas problematizações nascidas de um contexto que precisa ser levado em consideração. Àquilo a que tanto insistimos explorar na prática docente, chamando de valorização do contexto cultural, histórico e político do lugar, revela-se como o ponto inicial de uma condição ética a qual todo e qualquer docente terá de se atentar: seja pelos aspectos singulares que cada escola, comunidade, grupo trazem, sejam pelas novas dimensões político-sociais que norteiam currículos e regras instrutivas para o funcionamento da educação formal. De todo modo, há de se avaliar, a partir de um juízo e, posteriormente, de uma apreciação mediada pela sensibilidade histórica e cultural, sobre quais as melhores formas de se construir um discurso pedagógico naquele lugar, especialmente, quais estratégias se aproximarão de um conteúdo junto às emergências daquele espaço serão eficazes.

Ainda no que diz respeito à diferenciação entre Ética e Moral exposta por Lalande (1993), ressaltamos aqui como a segunda, por ser um conjunto de regras admitidas por um grupo em um determinado tempo e contexto, quando sobreposta à Ética, conduz o professor a dificuldades de se lidar com aquilo que difere de seu próprio universo íntimo e cultural. Ou seja, o que queremos apontar neste texto é que, para o futuro professor, sua atenção deve valer-se à ética enquanto possibilidade de apreciação e ajuizamento acerca dos atos sem sobrepor suas crenças morais às dos outros sujeitos no contexto de sala de aula. Este é um dos primeiros aspectos formativos ao qual o futuro professor precisa se atentar.

A Estética, disciplina filosófica do séc. XVIII (BAUMGARTEN, 1993), evidencia, em seu caráter epistemológico como há uma construção de saber sensível sobre o sujeito ao longo da história da humanidade - embora tenha sido reconhecida tardiamente enquanto área de conhecimento filosófico. Também não é novidade como as confrontações entre ética e estética norteiam a condição do sujeito moderno e contemporâneo, especialmente por assumirem, em sua gênese, o espaço do conflito. No caso da Estética, sua ontologia está no antigo confronto ente a 
DOI: $10.12957 / \mathrm{e}-\mathrm{mosaicos} .2019 .46561$

sensação e razão, entre o inteligível e o intuitivo, o que nos encaminha para uma problemática contemporânea espinhosa: a forma e o efeito estético da forma enquanto este é superficial e seduz sem nenhuma demora ou reflexão, aquele exige uma fruição e entendimento, se pensarmos a partir de Kant (2015).

Diante de um contexto atual problematicamente envolvido com as novas formas comunicacionais e de relações sociais e a exploração exacerbada do intuitivo em desconsideração ao inteligível, sem a estética, é complexo alcançar a dimensão dos novos paradigmas educacionais, especialmente, no que tangem uma insistente desconsideração de saberes históricos, científicos e legitimados ao longo de séculos, hoje sobrepostos por falácias esvaziadas, porém, carregadas de efeito estético.

\section{CEnÁRIOS POLÍticos e nOVOS PARADIgMAS}

A noção de paradigma, trazida por Thomas Kunh em Estrutura das revoluções científicas (2017), é apresentada como algo que se adere por convencimento, ou seja, a partir de observações, identificações e generalizações, consegue-se pensar em algo que fundamenta um objeto de reflexão. Ainda em Kuhn, é possível compreender como os paradigmas não são fixos, pois evidenciam uma escolha de observação, logo, compõem o recorte de um debate ou investigação, a partir de parâmetros. No caso da educação, por não se deslocar da história, os paradigmas são reconfigurados ao longo dos tempos, fazendo com que o docente precise compreender quais os novos paradigmas comtemplam as atuais problemáticas que compõem o universo de ensino formal no Brasil.

Ao situar-se em um tempo e espaço na busca por compreensão de quais lugares teóricos e reflexivos está se falando em contexto de formação e prática docente, o debate promovido no âmbito da licenciatura está preocupado em destacar como existe uma construção histórica importante no contexto de ensino e aprendizagem e de como a compreensão desse processo permite confrontar práticas e teorias que não dialogam com as atuais emergências educativas. Neste sentido, valemo-nos da necessidade de se retomar gestos contextuais que fomentam a construção de discursos pedagógicos no âmbito de ensino em Artes Visuais, chamando atenção ao fato de que rupturas epistemológicas constroem lacunas sérias quanto à consciência da prática docente, especialmente por negligenciar fatores importantes. Isso não significa não problematizá-los, mas enfrenta-los junto aos novos fundamentos que complexibilizam o ensino em artes.

Assim, um dos maiores esforços nos atuais debates sobre educação no Brasil consiste em compreender as políticas acerca das reformas feitas, tanto no contexto de base quanto especificadas no Ensino Médio. No que diz respeito à Base Nacional 
DOI: $10.12957 / \mathrm{e}-\mathrm{mosaicos} .2019 .46561$

Comum Curricular ${ }^{3}$, o componente curricular de Artes para o Ensino Fundamental atenta-se às necessidades de aprendizagens diversas, com destaque para Artes Visuais como espaço de saberes sobre traços, cores, tons e formas, ocupantes de um campo maior: o de linguagens - unem-se à Arte as disciplinas de Línguas Portuguesa e Educação Física.

Quanto ao Ensino Médio, Artes Visuais concentra-se apenas em um eixo de um componente maior, Arte, dentro de uma grande área de conhecimento: Linguagens e suas tecnologias. O texto final fala de uma preocupação com o protagonismo dessas linguagens como campo de saber sem se ater às especificidades epistemológicas de seus campos de conhecimento. Preocupa-nos o fato da formação docente do professor de Artes Visuais ter de se ater a outros saberes que não são específicos do campo das visualidades e provoquem, nos futuros docentes, a necessidade de se lidar com uma polivalência que poderá fragilizar espaços de discussão já consolidados.

Contudo, o que queremos chamar atenção, neste texto, é para a complexidade de se lidar com os futuros docentes, no contexto de Estágio Supervisionado, a partir de uma compreensão e relações observadas acerca da BNCC e dos espaços de atuação locais - especialmente considerando realidades complexas e divergências entre esferas administrativas, acesso a materiais didáticos e espaços para colocar em prática as exigências de desenvolvimento das habilidades elencadas pela reforma curricular (problemas já conhecidos no âmbito da educação no Brasil). Desse modo, acreditamos que a prática docente por meio do estágio configura, não só um laboratório de experiências acerca da docência, a partir da observação e regência, mas um terreno fecundo de possibilidades reflexivas sobre o campo de conhecimento das Artes Visuais, considerando suas fragilidades, sua história e sua ainda complexa ocupação de espaço no contexto formativo básico. Vale ressaltar que tais experiências conduzem o futuro professor a identificações de problemáticas como forma de pensa-las a partir de projetos, escolhas metodológicas e abordagens variadas, desmitificando a ideia de que existe um modelo-chave de ensino em artes visuais e que ele pode ser aplicado em sala de aula com sucesso.

\section{O ESTÁGIO SUPERVISIONADO COMO ESPAÇO DE TEORIA, PRÁTICA E REFLEXÃo}

No contexto do Curso de Artes Visuais - Licenciatura, a preocupação com os Estágios Supervisionados implica em explorar, junto aos alunos, competências quanto à inteligência perceptiva, pensada enquanto docência, mas também, explorada no ato do ensinar. Ensinar Artes Visuais implica, na verdade, explorar e ajudar a construir saberes que nascem através do sensível e inteligível, desenvolvendo a partir dessas percepções e cognições, conhecimentos acerca de si, do outro e do mundo. É a partir da consciência dessa sensibilidade que se pode

${ }^{3}$ Disponível em: <http://basenacionalcomum.mec.gov.br/> Acesso em novembro de 2019. 
DOI: $10.12957 / \mathrm{e}-\mathrm{mosaicos} .2019 .46561$

alcançar reflexões sobre questões humanas, sociais, políticas, culturais etc.

Ao apresentarmos o presente artigo, tencionamos questões que afetam a formação de professores e a dinâmica da função docente, no sentido de consideramos a nossa função como um mecanismo de ensino e de pesquisa no âmbito dos Estágios Supervisionados. No contexto da formação em Artes Visuais, nos preocupamos com a dimensão pedagógica da reforma do Ensino Médio, assim como, os efeitos ampliados da $\mathrm{BNCC}^{4}$, pois a mesma atravanca práticas escolares que permitem acesso à diversidade das produções culturais, não apenas hegemônicas, mas aquelas que contemplam outros olhares envolvendo a arte brasileira, a cultura latino-americana, bem como, a produção de mulheres negras e de negros, de povos indígenas e da cultura popular (VASCONCELLOS; STORCK; MOMOLI, 2018, p. 254).

Em se tratando das perspectivas do "novo" Ensino Médio, acredita-se que os esforços na docência em Estágio Supervisionado deverão alinhar os saberes sensíveis e inteligíveis às complexidades daquilo que toca às linguagens e suas formas bem como as tecnologias que as confrontam e as reinventam. Desse modo e alinhando nosso pensamento ao de Pimenta e Lima (2012), o estágio se pretende como um espaço fecundo de conhecimento e, portanto, de caráter epistemológico em que há a necessidade evidente de diálogo entre conhecimento e ação.

Ao assumirmos o estágio como espaço de conhecimento, investigação e formação, é possível lidar com as impressões trazidas pelas experiências de campo vivenciadas pelos alunos como elemento de possibilidade de conhecimento, a partir de perguntas como: por que se utilizam essa abordagem para lidar pedagogicamente com este assunto? Por que o professor regente opta por este recurso? Como as exigências curriculares são dialogadas com questões locais e contemporâneas, sem que se negligencie assuntos, mas aproximando-os de uma realidade? Como explorar uma capacidade perceptiva acerca de assuntos que tocam questões culturais, éticas, morais, religiosas etc.? Como, no ensino de Artes Visuais, as visualidades contemporâneas merecem espaço de discussão como forma estética que fomentam e denunciam? Não há professor se não há gesto investigativo. $E$ isso é necessário de ser provocado no momento do estágio supervisionado. Seja por sua característica genuína de alinhar teoria e prática, seja pelas dificuldades enfrentadas entre o espaço teórico e acadêmico de discussão e a realidade cotidiana do ensino básico, é pelo estágio que se pode, ao menos, buscar esforços para lidar com estes questionamentos e enfrenta-los de modo mais palpável junto ao futuro professor.

Ainda de acordo com Pimenta e Lima (2012), que assumem a profissão do professor como uma profissão da prática social, em que se alinha uma prática à teoria como forma de ser, pensar e estar no mundo, o estágio é aqui pensado como lugar de diálogo acerca dos diferentes fenômenos e contextos observados na sala de

\footnotetext{
${ }^{4}$ A elaboração da proposta relacionada com a BNCC iniciou-se no ano de 2014 em consonância com o processo de reestruturação do Sistema Nacional de Educação.
} 
DOI: $10.12957 / \mathrm{e}-\mathrm{mosaicos} .2019 .46561$

aula. A práxis, não como negação da teoria, mas como espaço prático em que se pensa a teoria, é uma forma de superar a separação problemática entre teoria e prática, especialmente por buscar aproximações com a realidade - esta, o principal instrumento da práxis pedagógica.

\section{PrÁxis docente e A RECEPTIVIDADE DISCENTE}

As questões elencadas sobre a práxis docente e a receptividade discente resultam de um movimento de pesquisa e reflexão crítica acerca da relevância dialógica presente na interação entre professores e alunos. De acordo com Penteado (2010), este movimento coincide com uma perspectiva que privilegia tanto a pesquisa como o ensino, resultando em um processo metodológico que caminha em consonância com o fazer e a atuação docente. Desse modo, entendemos que "essa atuação visa à vivência de condutas investigativas na prática de ensino, que permitam exercê-lo como um processo criativo do saber docente" (PENTEADO, 2010, p. 36). A atuação docente em diálogo e interação com os discentes a partir de condicionantes que perpassam o saber escolar, como uma dimensão investigativa que problematiza e interroga o próprio ato de ensinar.

Dentre um conjunto de disciplinas que organizam o currículo na formação de professores em Artes Visuais, a Disciplina de Estágio Supervisionado requer um olhar atento e cuidadoso. Esta disciplina em questão reverbera nuances subjetivas que são vivenciadas pelos discentes, desde a época de escolarização até a finalização da formação na licenciatura. Na perspectiva apresentada por Hernández (2005), temos que pensar um modelo de formação maleável e acessível, que desencadeie processos formativos nos "futuros docentes" numa dimensão que relacione o desenvolvimento de conhecimentos, assim como, a construção de competências relacionadas tanto com a realidade da educação em seus diferentes níveis como a própria experiência dos discentes. Essa dimensão da experiência discente reflete, inclusive, o caráter vivenciado a partir da construção subjetiva dos próprios sujeitos. Ao considerar essa dimensão, estamos atentos às questões que, até então, perpassam os interesses pedagógicos na perspectiva curricular do ensino médio. Questões que transitam sobre temas ampliados e que dialogam com o "[...] reconhecimento da subjetividade do sujeito, no livre diálogo entre estudantes e professores, na participação democrática ou na construção de um conhecimento não fragmentado e não alheio à experiência dos alunos" (CARBONELL, 2016, p. 55). Considerar essa perspectiva formativa constitui um caminho promissor para 0 processo de uma aprendizagem critica e dialógica, em especial, aquela que pressupõe uma práxis docente em consonância com a receptividade discente.

Esse movimento receptivo é um componente importante sobre os efeitos primários e imediatos acerca das reformas curriculares. Também é um fator que conduzem os licenciados a um olhar desperto no que diz respeito à compreensão 
DOI: $10.12957 / \mathrm{e}-\mathrm{mosaicos} .2019 .46561$

estrutural de suas experiências vividas enquanto aluno de educação básica em confronto com as novas experiências vivenciadas no campo do estágio, norteado por uma visão curricular e estrutural que amplia o campo de entendimento do aluno sobre o panorama e as especificidades ditadas por cada unidade escolar. Chama-nos atenção o fato de que as impressões que direcionam as discussões teóricas sobre a prática de estágio são oriundas desse lugar de recepção.

Pimenta e Lima (2012), assim como Hernández (2005), corroboram com a ideia de que há a necessidade de um movimento de construção de conhecimento a partir da prática de estágio que não se desvincula de um processo de construção de identidade docente. Isso é reforçado pelo processo de convergência entre a experiência de estágio junto ao reconhecimento dessa experiência como parte integrante de um processo complexo de entendimento subjetivo do ensinar, especialmente, do ensinar Artes Visuais.

\section{CONSIDERAÇÕES FINAIS}

Retomando as perguntas feitas ainda no início deste texto ao longo das reflexões aqui trazidas e das experiências refletidas, nota-se que, nas novas políticas educativas enquanto base comum curricular há um esforço em dar conta de emergências que tocam a contemporaneidade em suas variadas problematizações, especialmente pelos espaços ocupados pelas novas tecnologias, o mass media e os novos formatos comunicacionais. Contudo, atentos ao lugar que as Artes Visuais ocupa no grande campo de conhecimento das Linguagens, para nós, é possível que hajam efeitos que esbarrem diretamente no constructo dessa área de conhecimento, que ainda encontra-se em consolidação no campo educativo - especialmente quando se notam as múltiplas e problemáticas interpretações sobre a "função de um professor de artes visuais" na escola. Fora isto, há ainda o conflito de tentar concentrar as Artes Visuais no âmbito das Linguagens, problemática que, para nós, considera esta área de conhecimento, quando no contexto educativo, uma linguagem a ser ensinada.

Quando anunciamos nosso texto como espaço de pensar a reforma curricular a partir do estágio, intencionamos pensar: como o estágio em Artes Visuais é campo de investigação e conhecimento (PIMENTA e LIMA, 2012); como, a partir do espaço de discussão entre teoria e prática se pode evocar discussões importantes que evidenciam as novas problemáticas educativas e suas emergências; como a educação básica precisa estar em diálogo constante com a universidade e vice-versa, mediado por projetos e atividades que promovam essas aproximações, tal como nos faz ver Nóvoa (2017). As questões apontadas nos inquietam, tornando o nosso cotidiano permeado de incertezas que, afligem tanto os docentes como os discentes, 
DOI: $10.12957 / \mathrm{e}-\mathrm{mosaicos} .2019 .46561$

em especial, aqueles discentes que estão cursando a Disciplina de Estágio Supervisionado. Acreditamos que por ora não temos as respostas necessárias para dar conta de tantas inquietudes. Sabemos, por enquanto, que os desafios do ensinar e aprender em tempos de transição exige de todos nós uma postura atenta a esses conflitos que permeiam o campo da formação de professores: sejam eles éticos, estéticos, paradigmáticos, estruturais, mas principalmente, subjetivos.

\section{REFERÊNCIAS}

BAUMGARTEN, Alexandre G. Estética - A lógica da arte e do poema. Tradução Mirian S. Medeiros. Petrópolis, RJ: Vozes, 1993.

CARBONELL, Jaume. Pedagogias do século XXI: bases para a inovação educativa. Tradução: Juliana dos Santos Padilha. Porto Alegre: Penso, 2016.

HERNÁNDEZ, Fernando. A construção da subjetividade docente como base para uma proposta de formação inicial de professore de Artes Visuais. In: OLIVEIRA, Marilda Oliveira de; HERNÁNDEZ, Fernando (Orgs. ). A formação do professor e o ensino das Artes Visuais. Santa Maria, Editora: UFSM, 2005, p. 21-42.

KANT, I. Crítica da razão pura. Tradução Fernando Costa Mattos. Petrópolis, RJ: Vozes; Ed. Universitária São Francisco, 2015.

KUHN, T. S. A estrutura das revoluções científicas. Tradução Beatriz Vianna Boeira e Nelson Boeira. São Paulo: Perspectiva, 2017.

LALANDE, André. Vocabulário técnico e crítico da filosofia. Tradução Fátima Sá Correia. São Paulo: Martins Fontes, 1993.

NOVOA, António. Firmar a posição como professor, afirmar a profissão docente. Cad. Pesquisa. [online]. 2017, vol.47, n. 166, pp.1106-113. Disponível em:

http://www.scielo.br/scielo.php?pid=S0100-

$15742017000401106 \&$ script=sci abstract\&tlng=pt Acesso em Janeiro de 2019.

PENTEADO, Heloísa Dupas. Pesquisa-ensino: uma modalidade de pesquisa-ação. In: PENTEADO, Heloísa Dupas; GARRIDO, Elsa (Orgs.). Pesquisa-ensino: a comunicação escolar na formação do professor. São Paulo: Editora Paulinas, 2010. p. 33-44.

PIMENTA, Selma Garrido. LIMA, Maria Socorro Lucena. Estágio e docência. 7a ed. São Paulo: Cortez, 2012.

VASCONCELLOS, Sonia Tramujas; STORCK, Karine; MOMOLI, Daniel Bruno. Para onde caminha o ensino das Artes Visuais. In: Revista GEARTE, Porto Alegre, v. 5, $\mathrm{n}$. 
DOI: $10.12957 / \mathrm{e}-\mathrm{mosaicos} .2019 .46561$

2, p. 245-258, maio/ago. 2018. Disponivel em:

<http://seer.ufrgs.br/gearte/issue/view/3555> Acesso em 10 agosto de 2018.

Recebido em 10 de novembro de 2019

Aceito em 16 de dezembro de 2019

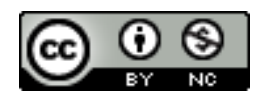

A e-Mosaicos Revista Multidisciplinar de Ensino, Pesquisa, Extensão e Cultura do Instituto de Aplicação Fernando Rodrigues da Silveira (CAp-UERJ) está licenciada com uma Licença Creative Commons - Atribuição-NãoComercial 4.0 Internacional.

Os direitos autorais de todos os trabalhos publicados na revista pertencem ao(s) seu(s) autor(es) e coautor(es), com o direito de primeira publicação cedido à e-Mosaicos.

Os artigos publicados são de acesso público, de uso gratuito, com atribuição de autoria obrigatória, para aplicações de finalidade educacional e não-comercial, de acordo com o modelo de licenciamento Creative Commons adotado pela revista. 